\title{
Reflection on Law Relief for Immunization Dispute of China
}

\author{
Yuqing Zhang \\ College of Humanities \\ Hubei University of Chinese Medicine \\ Wuhan, China
}

\begin{abstract}
Since the implementation of the immunization, it has made great contributions to the prevention and control of infectious diseases in China, and has raised the overall health level of our citizens. However, the damage caused by immunization is difficult to completely eradicate. Many recipients suffer severe physical damage after receiving the immunization, but limited to the current relief system is still imperfect, victims of adverse consequences of immunization are often difficult to obtain relief. In this paper, immunization related concepts, the domestic legislative situation associated with legal relationship, the prevention and the problems of foreign relief adverse consequences of the four aspects of the system research and analysis put forward to improve the immunization adverse consequences of relief system of China should.
\end{abstract}

Keywords-immunization; adverse reaction; compensation mechanism; law relief

\section{INTRODUCTION}

Immunization, as one of the most significant achievements in public health field in the 20th century, makes outstanding contribution to prevention and control of infectious diseases; however, adverse events following immunization come and lead to more and more injuries. Therefore, clarifying the legal nature and responsibility of immunization and building effective legal relief mechanism are of great significance.

\section{LEGAL NATURE AND RESPONSIBILITY OF IMMUNIZATION DISPUTE}

\section{A. Vaccine Quality Dispute}

Vaccine quality dispute refers to dispute arising from recipient suffering injury due to vaccine quality being not in line with the national drug standard. In accordance with the Product Quality Law, "vaccine not comply with the national standard will be regarded as defective product, which, if any, leads to injury of recipient, shall bear civil liability for injury caused by defective product". According to Article 59, Tort Liability Law, "in case of injury due to defective medicine, disinfecting agent and medical device or disqualified blood transfused, the patient shall be entitled to claim for compensation against the producer or blood provider or the medical institution. For claim against the medical institution, upon compensation, the medical institution shall have the right to claim compensation from the producer or the blood provider." The vaccine producer and the vaccinating unit shall bear unreal joint and several liabilities.

\section{B. Inappropriate Immunization Dispute}

Inappropriate immunization dispute refers to dispute arising from recipient suffering injury due to the vaccinating unit vaccinating in a wrongful way against the immunization stipulation. According to the Regulation for Management of Vaccine Circulation and Immunization, "the vaccinating unit shall strictly comply with the immunization procedure, immunity procedure, guideline for vaccine use and obligation of immunization". Thus it can be seen that the responsible subject for inappropriate immunization dispute is the vaccinating unit. According to Article 58 of Tort Liability Law, the tort responsibility of inappropriate immunization shall be subject to the principle of Presumption of Attribution, performing imposition of liability that the vaccinating unit shall bear the burden of persuasion to prove that they are subjectively free from fault; otherwise the unit shall be presumed guilty and liable in tort.

\section{Adverse Events Following Immunization Dispute}

Vaccinating adverse reaction includes normal events and adverse events. Normal event is spontaneously caused by vaccine with slight injury that it can be recovered relatively fast, so that no provision on claim or compensation for normal events is made by any country. While because the adverse events may lead permanent severe injury to the recipients, so that the victims are eagerly seeking for relief.

1) Adverse events following immunization dispute of the first type of vaccine: The immunization of the first type of vaccine produces administration legal relationship, which is a specific administrative act. Citizens have the obligation to vaccinate the vaccine, and the Government is responsible for overseeing the quality and immunization of the vaccine. In accordance with the Regulation for Management of Vaccine Circulation and Immunization, "in case of death, severe disability or organ damage of the recipient due to adverse events, the recipient shall be entitled to one-time compensation. In addition, the compensation fees shall be made by the financial department of the people's governments of the provinces, autonomous regions and municipalities for 
adverse events dispute of immunization of the first type of vaccine, if any". Thus it can be seen that for adverse events following immunization dispute of the first type of vaccine, the state shall assume the responsibility for compensation.

2) Adverse events following immunization dispute of the second type of vaccine: Adverse events following immunization dispute of the second type of vaccine belongs to ordinary medical dispute, applicable to Tort Liability Law Article 24, "If both the victim and the actor have no fault to the injury, the loss shall be shared by both parties according to the actual situation", which is a reflection of the principle of fairness. In accordance with the Regulation for Management of Vaccine Circulation and Immunization, Article 46, Clause 2 , "The compensation fee shall be borne by the relevant vaccine production enterprise for adverse events dispute of immunization of the second type of vaccine, if any." It can be seen that the vaccine production enterprise shall assume the responsibility for compensation.

TABLE I. LAWS AND REGULATIONS RELATED TO IMMUNIZATION IN CHINA (2000-2017)

\begin{tabular}{|c|c|c|}
\hline Date & Name & Main content \\
\hline $\begin{array}{l}2000 \\
\text { revised }\end{array}$ & $\begin{array}{l}\text { Product Quality } \\
\text { Law }\end{array}$ & $\begin{array}{l}\text { The liability for personal and property } \\
\text { damage caused by defective product } \\
\text { clarifies the subject of responsibility, the } \\
\text { way to bear responsibility and the scope } \\
\text { of compensation. }\end{array}$ \\
\hline $\begin{array}{l}2001 \\
\text { revised }\end{array}$ & $\begin{array}{l}\text { Drug } \\
\text { Administration } \\
\text { Act }\end{array}$ & $\begin{array}{l}\text { The vaccine producer must have the } \\
\text { national production approval number } \\
\text { and the quality, packaging, labeling and } \\
\text { instructions of the vaccine must comply } \\
\text { with the requirements. }\end{array}$ \\
\hline 2008 & $\begin{array}{l}\text { Method for } \\
\text { Identification of } \\
\text { Adverse Events } \\
\text { Following } \\
\text { Immunization }\end{array}$ & $\begin{array}{l}\text { It specifies the procedures for the } \\
\text { application, hearing and identification of } \\
\text { adverse events. }\end{array}$ \\
\hline 2010 & Tort Liability Law & $\begin{array}{l}\text { The Article } 59 \text { specifies the principle of } \\
\text { non-fault liability for the injury of } \\
\text { medical products, and specifies the } \\
\text { unreal joint liability of the producer and } \\
\text { seller. In addition, the Article } 47 \text { also } \\
\text { provides a punitive compensation clause } \\
\text { for the product liability. }\end{array}$ \\
\hline $\begin{array}{l}2016 \\
\text { revised }\end{array}$ & $\begin{array}{l}\text { Regulation for } \\
\text { Management of } \\
\text { Vaccine } \\
\text { Circulation and } \\
\text { Immunization, }\end{array}$ & $\begin{array}{l}\text { It specifies the full-course tracking and } \\
\text { co-operation mechanism of vaccine to } \\
\text { avoid the possibility that the vaccine } \\
\text { flows into the illegal channel. At the } \\
\text { same time, it strengthens efforts to the } \\
\text { responsibility for the supervision of } \\
\text { vaccine circulation, supervise and trace } \\
\text { all stages of vaccine production, } \\
\text { circulation, transportation, preservation } \\
\text { and immunization. }\end{array}$ \\
\hline 2017 & $\begin{array}{l}\text { Code for } \\
\text { Management of } \\
\text { Vaccine Storage } \\
\text { and } \\
\text { Transportation }\end{array}$ & $\begin{array}{l}\text { It is applicable to the management of the } \\
\text { vaccine storage and transportation } \\
\text { process specified in the Regulations. }\end{array}$ \\
\hline
\end{tabular}

\section{PROBLEMS IN THE LEGAL RELIEF OF THE IMMUNIZATION DISPUTE IN CHINA}

\section{A. Differences in Relief Compensation Methods}

1) Compensation methods introduced in succession: In accordance with the Regulation for Management of Vaccine Circulation and Immunization, "The specific compensation method for the adverse events following immunization shall be formulated by the people's governments of the provinces, autonomous regions and municipalities."At present, all the 31 provinces, autonomous regions and municipalities, except Hong Kong, Macao and Taiwan, have formally promulgated the relevant documents. And Qinghai is the earliest province to promulgate (2008) while Guizhou is the last one (2015).

2) Regional differences in relief compensation methods: Differences existing in policy nature, formulation subject, issue time, scope of application, compensation fund, compensation calculation basis, and compensation procedure, etc. may lead to "same life or disease with different price" situation in relief compensation.

a) Other medical expenses not being paid separately in individual areas: Although all the compensation methods introduced in various places are "One-time" compensation, there are more or less differences existing in the specific compensation method. "Beijing compensation method for general adverse events contains 'Nursing fee', 'lost wages' and other basic expenses; Guangdong, on the above basis, adds 'disability appraisal fee' and 'Transportation expenses'; and Henan also includes the 'accommodation expenses. However, Hebei, Zhejiang, Sichuan and Heilongjiang, etc. make clear that they will not pay the above fees separately except the basic expenses."

b) Difference of the upper limits among thecompensation amount and the year: Some provinces draft corresponding compensation factor based on the per capita disposable income of their residences while some directly set the maximum compensation amount and the year. Because of the different disposable incomes and other objective conditions, there is differences existing in the actual compensation amount, which forms the same damage situation, and the standard of compensation year in different regions is quite different.
For the investigation of methods for compensation of Immunization Adverse events of 31 provinces see http://news.sina.com.cn/o/2015-1028/doc-ifxizwti7339452.shtml 
TABLE II. PROVISION ON COMPENSATION YEAR SPECIFIED IN THE METHOD FOR COMPENSATION AND RELIEF OF ADVERSE EVENTS FOLLOWING IMMUNIZATION

\begin{tabular}{|l|l|}
\hline \multicolumn{1}{|c|}{ Province } & \multicolumn{1}{c|}{ Compensation year } \\
\hline Beijing & 20 years at most \\
\hline Hebei & 10 years at most \\
\hline Hainan & 15 years at most \\
\hline Mongolia & $\begin{array}{l}\text { 10 years for recipient dead under 18 years old; 15 years } \\
\text { for recipient dead above 18 years old }\end{array}$ \\
\hline Guizhou & $\begin{array}{l}\text { 5 years for recipient dead under 3 years old due to } \\
\text { adverse events following immunization; 10 years for } \\
\text { recipient dead above 3 years old; 22 years for severe } \\
\text { injury. }\end{array}$ \\
\hline
\end{tabular}

In 2014, an infant recipient under 1 year old died due to adverse events of immunization can only obtain one-time compensation of 30,000 Yuan at highest in Hunan province, while in Beijing, it can obtain 806,420 Yuan, which is 26.88 times of the compensation fee of Hunan province. ${ }^{2}$

3) Unreasonable one-time compensation: According to the Regulation for Management of Vaccine Circulation and Immunization, Article 46, "one-time compensation shall be given to the recipient dead, severely disabled or suffering from organ or tissue injury caused by adverse events following immunization ${ }^{3}$." For "recipient severely disabled or suffering from organ or tissue injury", the recovery process is extremely difficult and lengthy. In addition to the physical pain and the hardships in the healing process, they bear a long-term mental stress and torture. A law adage said, "Power makes relief". Such one-time compensation method cannot provide comprehensive relief to the physical and psychological damage of the recipient, nor does it conform to the rule of law for respect and protection of human rights.

\section{B. Limited Objects to Be Relieved Against Adverse Reaction}

The objects to be relieved in our country are only limited to the injury caused by the adverse events following immunization of the first type of vaccine, however, some nonadverse events, in addition to normal events, same to the adverse events, like the cardiac reaction and coupling reaction, have great physical harm to the recipient too. Although there is a cause for the specific physical constitution of the recipient, as the ultimate victim of the injury, if they are not be compensated only because of their specific constitution or the like, but the individual and the family have to bear huge treatment and rehabilitation expenses, this will be contrary to the purpose of immunization - social public health, regardless of the protection of individual health.

Globally, all the Vaccine Compensation Act developed by the United Kingdom in 1979, Law of Immunization established by Japan in 1976 and National Vaccine Injury Act for Children developed by the US in 1986 do not put coincidental event in exemptions list. E.g. the Japanese Law of Immunization specifies that all the following descriptions are

2 For the investigation of methods for compensation of Immunization Adverse events of 31 provinces see http://news.sina.com.cn/o/2015-1028/doc-ifxizwti7339452.shtml

Immunization qualified to relief object of immunization: (1) adverse events caused by or suspected to be caused by compulsory immunization; (2) after-effects caused by or suspected to be caused by compulsory immunization; (3) death caused by or suspected to be caused by compulsory immunization. Relief compensation is also required for non-adverse events, which are the need of fair and harmonious social relations and the need to guarantee the health and interests of the whole people.

\section{Problems in the Identification of Adversereactions of Immunization}

1) The identification organization of adversereactions of immunizationis not of neutrality: It is specified in the Method for Identification of Adverse Events Following Immunization that, "for suspected adverse events, if any, the disease prevention and control agency shall take charge of investigation and diagnosis; in case of any dispute, it may apply to the municipal medical association for identification of adverse events following immunization; and if the dispute is not solved, it shall be applied to the provincial medical association for identification."

The disease prevention and control agency is the business management and technical support center for the prevention and control of diseases in the jurisdiction. If the group of experts is led by the disease prevention and control agency, it will lead to a situation of group of experts being both "referee" and again "Athletes". Some experts also serve in large medical institutions under the health administration department, which makes it easy for the health sector of "What I say goes" situation objectively, so that the victims and their families are also easy to question the identification process and appraisal results, then they will lose trust to the group, and it is not conducive to the legal settlement of disputes.

2) The identification of damage caused by adverse reaction is not included in the scope of judicial identification: It is very complicated to identify the adverse events of the immunization, and when this kind of dispute is applied to the court, the injury identification, as the decisive evidence, is not included in the business scope of judicial identification. Judicial identification, independent of major medical institutions, vaccinating units and vaccine producers, is different from the identification of the group of experts selected for investigation and diagnosis. The conclusion of judicial identification is of more authority and impartiality.

\section{Difficulties of Compensating Funds in Full}

At present, the compensation funds of our country are different due to different compensation subject. The first type of vaccine, which is compensated with the governmental financial department's work fund, is not only complicated in the provisions of the appraisal procedure, the compensation scope and the compensation amount, but also lacks the necessary legal basis and guarantee. "Generally, some compensation expenses are finally transferred to local finance 
to solve by themselves ${ }^{4}$, , so that the victim is not effectively compensated or with lower compensation fee ${ }^{5}$. The second type of vaccine, which is compensated by the production enterprise, on the one hand, costs more time and cost of dispute resolution that is not conductive to the victim to receive compensation in time, seize time for diagnosis, treatment and rehabilitation; on the other hand, causes enormous economic risks to the vaccine producers.

\section{SUGGESTIONS ON IMPROVEMENT OF THE LEGAL RELIEF FOR IMMUNIZATION-RELATED DISPUTE OF CHINA}

\section{A. Expansion of the Scope of the Relief Objects Suffering from Reverse Reaction}

As previously mentioned, many countries have established result-based relief principles, which will give compensation in case of any injury, regardless of fault. The cause of nonadverse events (such as coupling reaction, cardiac response) is difficult to verify, therefore, in consideration of the social public welfare, it is indeed necessary to expand the relief scope of non-adverse events and incorporate it into the scope of administrative compensation, which is conducive to safeguarding the life and health interests of the affected person. It also can better promote immunization, so that the recipient will have no trouble in the future.

\section{B. Perfection of the Identification System of Reverse Reaction}

1) Establishment of a third-party identification institution: It is suggested to establish independent third-party identification institutions and expert library. If an adverse events event occurs, randomly draw experts from the library to form expert group to conduct investigation and diagnosis. The expert group, from a neutral angle, shall make a fair identification of adverse reactions.

2) Inclusion of adverse reactions into the scope of juridical identification: It is recommended that the adverse reactions be included in juridical identification scope, and after entering the proceedings, the people's court and the parties entrust the legal identification agency to carry out the authentication and judgment. The identification result made by the legal identification agency will be more easily accepted by the parties involved in the dispute, and it is easier to dissolve the dispute by virtue of the credibility of the appraisal result given by the legal identification agency and truly realize the justice of the judicial system.

3) Establishment of special compensation fund forthe relief for vaccinating injury: By using the successful experience of the United States VICP Trust Fund system for reference, we can establish a risk transfer mode to transfer individual risks to the whole industry, which can reduce the risk of vaccine producers to the lowest, protect the

\footnotetext{
Zhang Jinxue, Zhaoping, Xu Zhenji. Opinion on the Affluence and Countermeasure of the Reverse Reaction Treatment of Immunization, China Health Industry, 2015, $9^{\text {th }}$ issue

Xie Xueying, Discussion on the Current Situation and Suggestions of Adverse events Treatment of Immunization of Taian City, China Foreign Medical Treatment, $20084^{\text {th }}$ issue.
}

development of vaccines while make the victims access to economic compensation.

The special compensation fund also needs to establish a perfect operation system, for example, it can establish a national reverse events following immunization foundation in the Ministry of Public Health or the State Food and Drug Administration in charge of fund operation; set foundation branch in the provincial Ministry of Public Health or the Food and Drug Administration in charge of relief fund collection and release; at the same time, it is necessary to establish a professional identification body of reverse events following immunization to judge whether the case is within the scope of relief. With reference to the United States relief system, the relief scope can be clarified and the relief items can show which losses or expenses are within the relief range, and the victim can better clarify the preparation of the application information, so that the clear definition is conductive to the implementation of the compensation to victim.

\section{Reduction of the Compensation Difference Among Different Provinces and Establishment of National Compensation System}

As mentioned above, the differences in compensation methods among the provinces have been above the acceptability of the public, resulting in "same cases with different judgments and compensations, which is not conducive to the unified planning of relief work nationwide. Therefore, it is necessary to intensify the exploration of more perfect relief system. The existence of regional differences may be unavoidable, but we must shorten the inter-provincial compensation differences continuously as much as possible.

The relief system of adverse events following immunization in China only specifies compensation but the national compensation system, and along with small amount of administrative compensation, the relief actually obtained from civil compensation is very limited that the victim of immunization is hard to acquire comprehensive relief. Hence, China can use the immunization relief system of Japan for reference to make up the loopholes in national compensation and put the relief for victims into practice.

\section{Implementation of the Risk-sharing Mechanism of Commercial Insurance}

The inclusion of adverse events following immunization into commercial insurance is a new risk-sharing mechanism. In the "Twelfth Five-Year Plan", Beijing has taken the lead in introducing the adverse events following immunization of the first type of vaccine into commercial insurance compensation mechanism, and comprehensively started to introduce the commercial insurance compensation mechanism into the fullcourse compensation of adverse events following immunization in 2016 to promote introducing the insurance mechanism of the adverse events following immunization of the second type of vaccine. As at January 2016, the compensation mechanism of adverse events following immunization of Jiangsu Province "transferred to insurance 
compensation from financial compensation" "To promote the establishment of a multi-level compensation system combining basic insurance and commercial supplementary insurance, and encourage the vaccine recipient to insure the commercial insurance for reverse events, the vaccinating unit to insure medical liability insurance, the vaccine producers to insure the product liability insurance and the insurance companies to design new insurance or combined insurance."

\section{CONCLUSION}

The insurance mechanism is inherently a kind of diversification mechanism that it can convert the loss may occur in the future into the insurance fee paid by the current policy holder through the operation of the insurance company, and disperse the individual risk into the whole industry, so as to gather the financial power of all policyholders to solve the huge loss risk for individuals. As a third-party processor and coordinator of the dispute arising from reverse events following immunization, insurance company can enhance the efficiency of dispute settlement, which alleviates the working pressure of the government to compensate the huge amount of the treatment and is beneficial to the harmonious stability of the society. However, the introduction of the insurance mechanism must pay attention to the provisions of the insurance liability and the mutual connection to governmental immunization work, so that the recipients can guarantee their known right of claim as much as possible.

\section{REFERENCES}

[1] For the investigation of methods for compensation of Immunization Adverse events of 31 provinces see http://news.sina.com.cn/o/2015-1028/doc-ifxizwti7339452.shtml.

[2] For the investigation of methods for compensation of Immunization Adverse events of 31 provinces see http://news.sina.com.cn/o/2015-1028/doc-ifxizwti7339452.shtml.

[3] Regulation for Management of Vaccine Circulation and Immunization

[4] Zhang Jinxue, Zhaoping, Xu Zhenji. Opinion on the Affluence and Countermeasure of the Reverse Reaction Treatment of Immunization, China Health Industry, 2015, 9th issue.

[5] Xie Xueying, Discussion on the Current Situation and Suggestions of Adverse events Treatment of Immunization of Taian City, China Foreign Medical Treatment, 2008 4th issue.

[6] New regulation! How to handle with the second type of vaccine? http://news.bioon.com/article/6681912.html.

[7] Notification on Reform and Improvement of The Compensation Mechanism of Reverse Events Following Immunization.

\footnotetext{
6 New regulation! How to handle with the second type of vaccine? http://news.bioon.com/article/6681912.html

$7 \quad$ Notification on Reform and Improvement of The Compensation

Mechanism of Reverse Events Following Immunization
} 